\title{
The GATA3 X308_Splice breast cancer mutation is a hormone context-dependent oncogenic driver
}

\author{
Natascha Hruschka ${ }^{1}$ - Mark Kalisz $\mathbb{1}^{2} \cdot$ Maria Subijana ${ }^{1} \cdot$ Osvaldo Graña-Castro ${ }^{3} \cdot$ Francisco Del Cano-Ochoa $\mathbb{C}^{4}$. \\ Laia Paré Brunet ${ }^{5,6}$. Igor Chernukhin ${ }^{7}$. Ana Sagrera ${ }^{2}$ - Aurelien De Reynies ${ }^{8}$ - Bernhard Kloesch ${ }^{1}$. \\ Suet-Feung Chin ${ }^{9} \cdot$ Octavio Burgués ${ }^{10,11} \cdot$ David Andreu (iD ${ }^{12} \cdot$ Begoña Bermejo $^{10,13} \cdot$ Juan Miguel Cejalvo $^{10,13}$. \\ Joe Sutton ${ }^{7} \cdot$ Carlos Caldas $\mathbb{D}^{9} \cdot$ Santiago Ramón-Maiques $\mathbb{D}^{4} \cdot$ Jason S. Carroll $\mathbb{D}^{7} \cdot$ Aleix $^{4}$ Prat $\mathbb{D}^{5,6}$. \\ Francisco X. Real (D) ${ }^{2,14}$. Paola Martinelli (D) $^{1,2,15}$
}

Received: 24 March 2020 / Revised: 11 June 2020 / Accepted: 16 June 2020 / Published online: 25 June 2020

(c) The Author(s) 2020. This article is published with open access

\begin{abstract}
As the catalog of oncogenic driver mutations is expanding, it becomes clear that alterations in a given gene might have different functions and should not be lumped into one class. The transcription factor GATA3 is a paradigm of this. We investigated the functions of the most common GATA3 mutation (X308_Splice) and five additional mutations, which converge into a neoprotein that we called "neoGATA3," associated with excellent prognosis in patients. Analysis of available molecular data from $>3000$ breast cancer patients revealed a dysregulation of the ER-dependent transcriptional response in tumors carrying neoGATA3-generating mutations. Mechanistic studies in vitro showed that neoGATA3 interferes with the transcriptional programs controlled by estrogen and progesterone receptors, without fully abrogating them. ChIP-Seq analysis indicated that ER binding is reduced in neoGATA3-expressing cells, especially at distal regions, suggesting that neoGATA3 interferes with the fine tuning of ER-dependent gene expression. This has opposite outputs in distinct hormonal context, having pro- or anti-proliferative effects, depending on the estrogen/progesterone ratio. Our data call for functional analyses of putative cancer drivers to guide clinical application.
\end{abstract}

These authors contributed equally: Natascha Hruschka, Mark Kalisz

Supplementary information The online version of this article (https:// doi.org/10.1038/s41388-020-1376-3) contains supplementary material, which is available to authorized users.

Paola Martinelli

paola.martinelli@boehringer-ingelheim.com

1 Institute of Cancer Research, Medical University Vienna, Comprehensive Cancer Center, Vienna, Austria

2 Epithelial Carcinogenesis Group, Spanish National Cancer Research Centre-CNIO, CIBERONC, Madrid, Spain

3 Bioinformatics Unit, Spanish National Cancer Research Centre-CNIO, Madrid, Spain

4 Department of Genome Dynamics and Function, Centro de Biología Molecular Severo Ochoa (CSIC-UAM), Madrid, Spain

5 Department of Medical Oncology, Hospital Clínic, Barcelona, Spain

6 Translational Genomics and Targeted Therapeutics in Solid Tumors, IDIBAPS, Barcelona, Spain

7 Cancer Research UK Cambridge Institute, University of Cambridge, Robinson Way, Cambridge CB2 ORE, UK

\section{Introduction}

Genomics studies have produced an expanding catalog of cancer-driving somatic mutations, which needs to be

8 Programme Cartes d'Identité des Tumeurs, Ligue Nationale Contre le Cancer, 75013 Paris, France

9 Department of Oncology, Cancer Research UK Cambridge Institute, University of Cambridge, Cambridge, UK

10 INCLIVA Biomedical Research Institute, Valencia, Spain

11 Pathology Department, Hospital Clínico UniversitarioCIBERONC, Valencia, Spain

12 Laboratory of Proteomics and Protein Chemistry, Universitat Pompeu Fabra, Barcelona, Spain

13 Oncology and Hematology Department, Hospital Clínico Universitario-CIBERONC, Valencia, Spain

14 Departament de Ciències Experimentals i de la Salut, Universitat Pompeu Fabra, Barcelona, Spain

15 Present address: Cancer Cell Signaling Department, Boehringer-Ingelheim RCV, Vienna, Austria 
translated into biological and clinically applicable knowledge [1]. One limitation of many studies is the tendency to lump all mutations occurring in one gene into a single class, which can lead to inconclusive results when stratifying patients in a binary fashion, as different genetic alterations might have distinct effects [2-4]. The GATA3 transcription factor is emerging as a paradigm of a gene where multiple classes of mutations occur, having distinct biological and clinical output [5-8]. This is specific for breast cancer (BC), where GATA3 is mutated in around $11 \%$ of cases and shows a characteristic mutational pattern, different from other tumor types [2, 3].

Several evidences implicate GATA3 in the activation of the mammary differentiation program: (1) in normal tissue, it is necessary for the luminal compartment formation [9]; (2) GATA3 expression in BC strongly correlates with estrogen receptor (ER) expression [10]; (3) GATA3 functions in a complex with FOXA1 and ER to enhance transcription of ER-responsive genes [11]; and (4) ectopic expression in GATA3-negative basal-like BC cells is sufficient to induce luminal differentiation and inhibit tumor dissemination [12]. Consistently, GATA3 expression decreases during progression to metastatic $\mathrm{BC}$ [13]. The high frequency of GATA3 mutations in BC suggests that they are driver mutations, but whether they result in loss-offunction (LOF) or gain-of-function (GOF) is not clear. Most GATA3 mutations are rare or unique frameshift indels (insertion/deletions) distributed along the $3^{\prime}$ gene end (Fig. 1a), consistent with the classical mutational pattern of a tumor suppressor and therefore suggesting a LOF [2]. However, they are typically heterozygous and the expression of the wild type (WT) allele is retained [14]. A few mutations concentrate in two clusters in exon 5 and 6 , including some "hotspots" or "warmspots," suggesting that they might generate GOF, instead. Whether GATA3 mutations are true oncogenic drivers is also an open question: while some in vitro and in vivo data suggest a tumorpromoting function $[6,8,15]$, in general they are associated with longer survival [2] and better response to endocrine therapy [16]. A recent study identified four classes of GATA3 frameshift mutations: (1) ZnFn2 mutations, occurring within the C-terminal $\mathrm{Zn}$ finger; (2) splice mutations, occurring mainly between intron 4 and exon 5; (3) truncating mutations, occurring downstream of the C-terminal $\mathrm{Zn}$ finger; and (4) extension mutations, occurring in exon 6 and disrupting the stop codon [6]. ZnFn2 mutations produce a highly stable truncated protein lacking the $\mathrm{C}$-terminal $\mathrm{Zn}$ finger, showing low affinity for DNA and altered transcriptional activity, and are associated with poor outcome when compared with other GATA3 mutations [6, 17]. Extension mutations produce a longer protein modulating drug sensitivity [5]. The effect of splice and truncating mutations remains unknown.
Here, we investigated the effects of the most prevalent GATA3 hotspot somatic mutation (X308_Splice). This mutation, like five additional ones producing partially or fully identical C-terminal peptides, correlates with better outcome in patients and is associated with a specific gene expression signature, characterized by altered ER-dependent transcriptional program. Combined analysis of patient-derived data and in vitro experiments with $\mathrm{BC}$ cell lines shows that the mutant protein - which we designate as "neoGATA3"interferes with the function of both ER and PR, blunting, without abrogating, their downstream programs. This has distinct biological outputs depending on the hormonal context: neoGATA3-expressing cells have a proliferative advantage when both estrogen and progesterone levels are high while they display a growth disadvantage when estrogen prevails. Our data suggest the existence of stage-dependent oncogenic effects of GATA3 driver mutations.

\section{Results}

\section{The GATA3 X308_splice mutation produces a unique neopeptide}

The most common GATA3 mutation is a 2 nt deletion in intron 4 disrupting the $3^{\prime}$ splice site (X308_Splice, Fig. 1a). The predicted effect is a transcript lacking 7 nucleotides $[7,14]$ which we successfully identified in RNA-Seq data from 15/19 TCGA-BRCA samples carrying the X308_Splice mutation but not in 20/20 tumors with either WT GATA3 or other GATA3 mutations (Fisher's exact probability test $P=1.54 \mathrm{e}-07$, Fig. $1 \mathrm{~b})$. The mutant transcript was validated by RT-qPCR in $4 / 4$ independent luminal A/B tumors carrying the X308_Splice mutation and in $0 / 7$ without it (Supplementary Fig. 1a). The loss of $7 \mathrm{nt}$ causes a frameshift, leading to a GATA3 protein-designated neoGATA3-lacking residues 308-444, encompassing the second $\mathrm{ZnFn}$, and containing instead a novel 44aa C-terminal sequence without homology to any other human protein sequence (Fig. 1c). We raised a polyclonal antiserum against the novel 44aa peptide, which specifically recognized a shorter GATA3 protein of the expected size $(37 \mathrm{kDa})$ exclusively in a tumor carrying the mutation and in cells transduced with the mutant cDNA (Fig. 1c and Supplementary Fig. 1b). These antibodies allowed the detection of neoGATA3 in a tissue microarray containing 100 luminal A/B tumors with information about GATA3 mutational status with high sensitivity (90\%) and specificity (94\%) (Fig. 1d).

Importantly, we identified five additional mutations, detected in six METABRIC and one TCGA-BRCA samples, producing fully or partially identical C-terminal peptides. One of them is a 2 nt insertion at codon Q321, found 
a

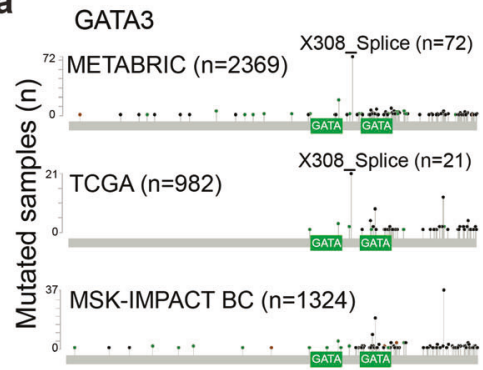

b

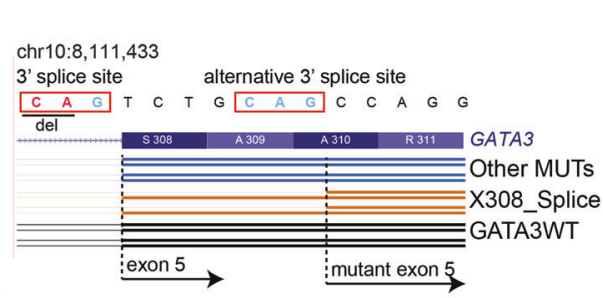

C

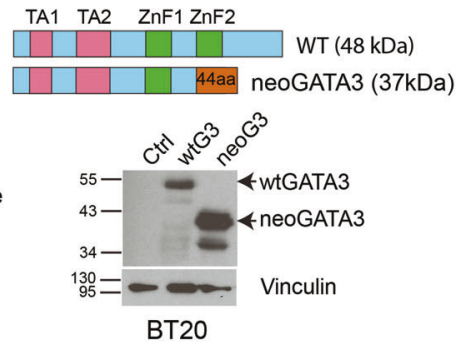

d

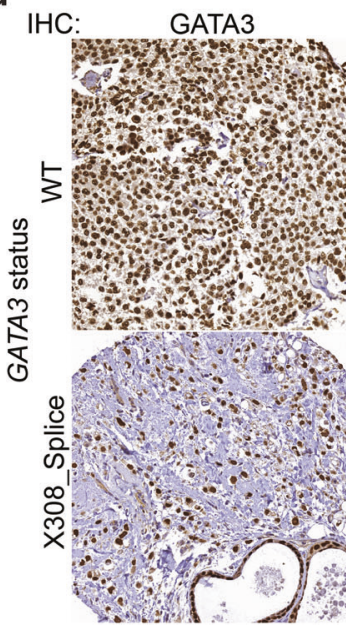

neOGATA3

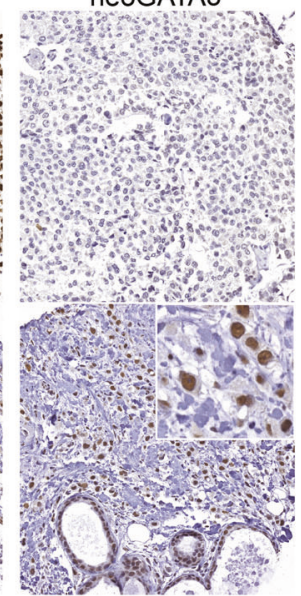

e

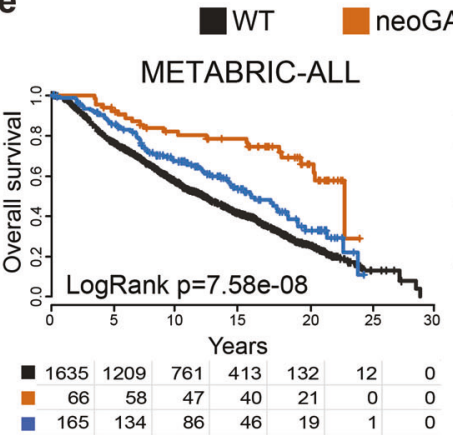

OtherMut

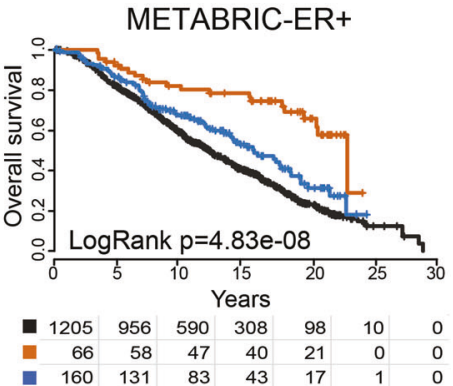

\begin{tabular}{llllll|} 
& \multicolumn{2}{c}{ METABRIC ALL } & \multicolumn{2}{c}{ METABRIC ER+ } \\
\hline & HR (CI 95\%) & p value & HR (CI 95\%) & p value \\
\hline neoGATA3 vs WT & $0.35(0.23-0.53)$ & $<0.001$ & $0.33(0.22-0.51)$ & $<0.001$ \\
\hline neoGATA3 vs OtherMut & $0.48(0.30-0.77)$ & 0.002 & $0.45(0.28-0.71)$ & 0.001 \\
\hline OtherMut vs neoGATA3 & $0.72(0.58-0.91)$ & 0.006 & $0.74(0.58-0.93)$ & 0.006 \\
\hline
\end{tabular}

GATA3 (wtG3) and the mutant neoGATA3. Black arrows indicate the proteins of the expected size. d Representative IHC images using either the N-ter GATA3 antibody-recognizing both wt and mutant GATA3 (left)—or the neoGATA3-specific antibody (right) on tumors carrying wild type GATA3 (top), or the X308_Splice mutation (bottom). e Kaplan-Meier survival curves of the METABRIC patients stratified according to GATA3 status (WT = wild type, neoGATA3 = all mutations producing a neoGATA3-like peptide, OtherMut $=$ all other mutations in GATA3). Left: all patients, right: ER + patients.

and with expression of progesterone receptor (PR) (Supplementary Fig. 2a-d), all factors predicting better outcome. Consistently, patients with neoGATA3-mutant tumors had significantly better overall survival (OS) compared to both patients with WT GATA3 (HR $=0.35$; 95\% CI 0.23-0.53; $P<0.001)$ and those carrying any other GATA3 mutation (OtherMut) $(\mathrm{HR}=0.48 ; 95 \%$ CI $0.30-0.77 ; P=0.002$, Fig. 1e, left).

Importantly, neoGATA3 mutations were exclusive for patients with ER + tumors (Supplementary Fig. 3a), which have better outcome [3, 18]. Even within this goodprognosis group, the presence of neoGATA3 mutations was strongly associated with significantly longer OS (neoGATA3 vs WT HR $=0.33 ; 95 \%$ CI $0.22-0.51 ; P<0.001$ and neoGATA3 vs OtherMut $\mathrm{HR}=0.45 ; 95 \% \quad \mathrm{CI}$ $0.28-0.72 ; P=0.001$, Fig. 1e, right). A tendency toward longer disease-free survival (DFS) was observed for patients with neoGATA3-mutant tumors in the TCGA-BRCA nificantly associated with lower tumor stage, grade, and size 
ER + cohort although the differences were not statistically significant, likely due to smaller sample size (Supplementary Fig. 3b). Univariate and multivariate analyses showed that neoGATA3 is an independent prognostic factor of longer OS and disease-specific survival (DSS) in the METABRIC cohort (OS: HR $=0.58 ; 95 \%$ CI $0.36-0.92 ; P$ $=0.02$; DSS: $\mathrm{HR}=0.46 ; 95 \%$ CI $0.23-0.94 ; P=0.03$; Supplementary Tables 2 and 3). Consistently, none of the 1324 patients with metastatic BC included in the MSKIMPACT cohort harbored neoGATA3 mutations [19] indicating that tumors with these mutations only metastasize exceptionally $(P<0.0001$, Fig. 1a).

Strikingly, approximately one-third of the neoGATA3 mutations occurred in METABRIC ER + patients below 50 years (Supplementary Fig. 3c, $P=0.0004$ ), suggesting that the effect of the neoGATA3 mutations might be affected by age or age-related factors, including the hormonal context.

To get insight into the molecular features of tumors harboring neoGATA3 mutations, we derived a gene expression signature based on a training set of 981 TCGABRCA samples (19 neoGATA3 mutations). This signature could identify neoGATA3-mutant tumors from the METABRIC series $(n=2001$ samples with expression and mutation data, 63 neoGATA3) with a sensitivity of $68.3 \%$ and specificity of $80.5 \%$ both when applied as a continuous variable and as binary classifier. When the signature was used to classify the samples from a cohort of patients with no available mutational data [20], patients with tumors classified as positive for the neoGATA3-signature (either as continuous or binary classifier) showed significantly longer DFS (LogRank $P=0.004$, not shown).

\section{Tumors with neoGATA3 mutations show changes in the immune microenvironment, not consistent with a T-cell mediated immune response}

A recent study identified the neopeptide of neoGATA3 as a potential neoantigen and suggested that it might induce an antitumor T-cell-dependent immune response and the activation of immune checkpoints [21]. To verify this hypothesis, we checked the expression of a set of markers of T-cell response in the METABRIC samples. Since neoGATA3 mutations are exclusive for ER + tumors, we only included these tumors in all our analyses. The expression of the T-cell marker CD8B (Mann-Whitney $U$ test $P=0.001$ ), and of the immune checkpoint protein PD-L1 $(P=0.033)$ was lower in neoGATA3 compared with WT tumors, while no significant difference was observed for CD8A and PD1 (Fig. 2a). To have a broader view of the immune landscape of neoGATA3 tumors, we used MCP counter to deconvolute the expression of immune markers and estimate the abundance of different cell populations [22]. A significant decrease in "CD8 + T cell" $(P=0.0003)$, "NK cell" $(P=0.01)$, and
"Cytotoxic lymphocyte" $(P=0.021)$ signatures was observed in the neoGATA3 tumors when compared with the WT tumors while the "T cell" signature was unchanged (Fig. 2b). We then analyzed the amount of CD8 $+\mathrm{T}$ cells in a set of FFPE sections from WT $(n=6)$ and neoGATA3 $(n=9)$ tumors by IHC for $\mathrm{CD} 8 \alpha$ protein. In accordance to gene expression data, $\mathrm{CD} 8+$ cells were significantly less abundant in neoGATA3 tumors (Fig. 2c, $P=0.048$ ). No significant differences at the single gene level were observed in the neoGATA3 tumors of the TCGA cohort (Supplementary Fig. 4a) but the "C4-lymphocyte depleted" immunoscore [23] was overrepresented among the neoGATA3 tumors (4/17 neoGATA3 versus $47 / 525 \mathrm{WT}$ ), although statistical significance was not reached ( $P=0.06$, not shown).

In addition, the neutrophil marker ELANE $(P=0.011)$ was significantly increased, whereas the M2-macrophage markers CD163 $(P=0.0002)$ and MSR1 (coding for CD204, $P=0.003$ ) were decreased in the neoGATA3 METABRIC tumors compared with WT (Fig. 2a) and showed similar tendencies in the TCGA-BRCA samples (Supplementary Fig. 4b). For some of the indicated markers, a significant difference was also observed when comparing neoGATA3 with OtherMut tumors (Fig. 2a, b). Although the differences between neoGATA3 and OtherMut tumors were rather small compared to the WT tumors, these observations suggest that the different mutations associate with distinct immune signatures. Consistent with these data, the MCP counter analyses revealed that the "Neutrophil" signature was upregulated $(P=0.04)$ and the "Monocytic lineage" signature was downregulated $(P=0.001)$ in the neoGATA3 tumors compared with WT, suggesting a complex modulation of the immune landscape in tumors carrying neoGATA3 mutations (Fig. 2b).

\section{Tumors with neoGATA3 mutations show decreased cell cycle progression and altered ER- and PR- dependent programs}

Gene set enrichment analysis (GSEA) of the genes differentially expressed in the neoGATA3 tumors compared with all other tumors, revealed a strong downregulation of cell cycleand inflammation-related Hallmarks gene sets (Fig. 3a). Accordingly, mRNA levels of E2F2 and E2F4, several cyclins, PCNA, and MKI67 were lower in the neoGATA3 METABRIC tumors (Fig. 3b) consistent with the better prognosis observed in patients. Similar differences were observed at the protein level in the TCGA series with reversephase protein arrays (RPPA) (Fig. 3c). This was not observed in tumors with other GATA3 mutations (Fig. 3b, c).

Among the genes upregulated in neoGATA3 tumors, we identified a significant enrichment of gene sets relative to estrogen response (both early and late), WNT/ $\beta$-catenin signaling, and apical junctions (Fig. 3a). Interestingly, the 

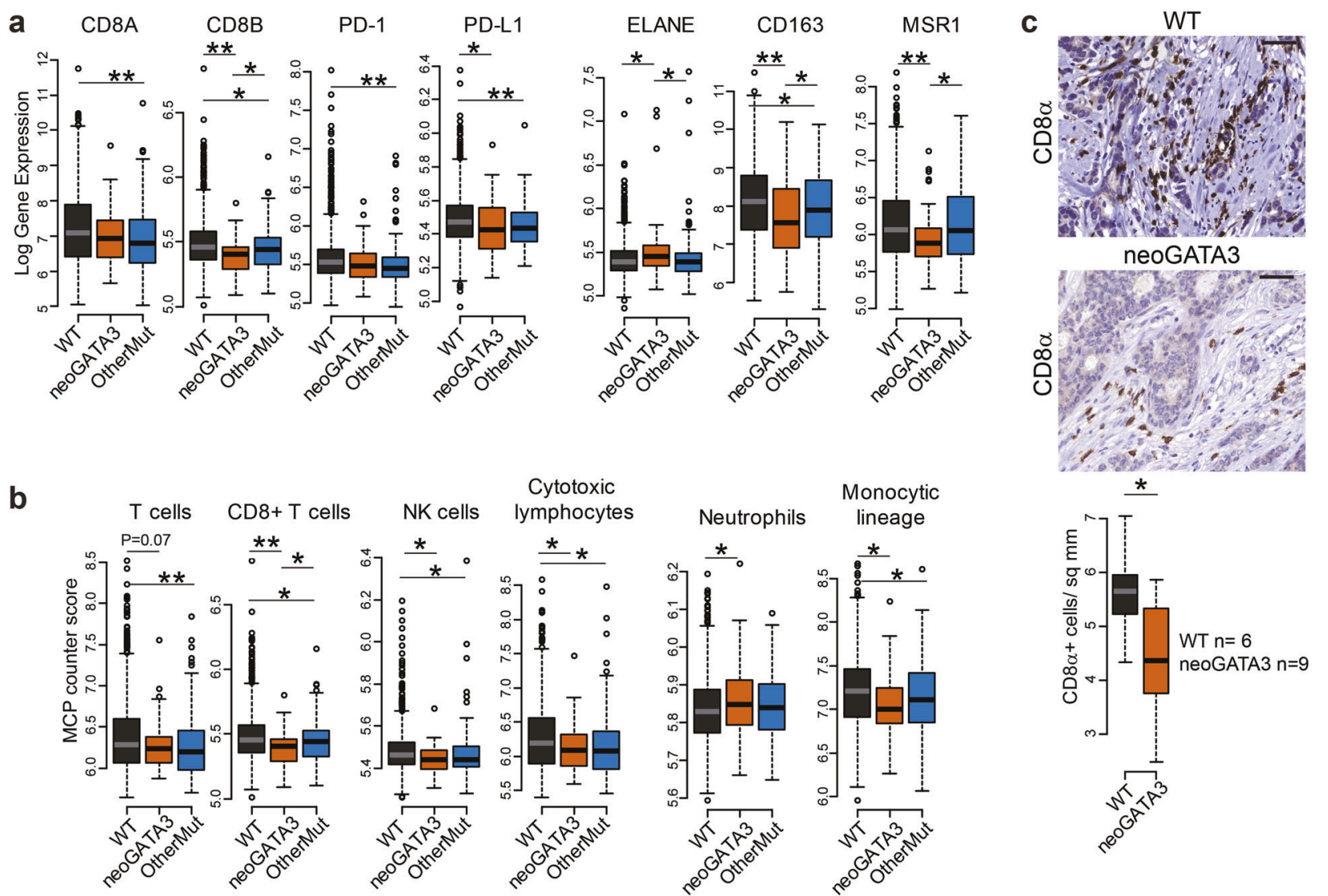

Fig. 2 NeoGATA3-mutant tumors do not display a prominent immune response. a Gene expression levels in tumors of the METABRIC ER + cohort, divided in the three groups according to GATA3 status (WT $n=1189$, neoGATA3 $n=66$, OtherMut $n=155$ ). b MCP counter scores for the indicated immune cell populations in the three groups of METABRIC ER + tumors (WT $n=1205$, neoGATA3

neoGATA3-associated transcriptome showed positive correlation with a published gene signature of good prognosis after endocrine therapy and negative correlation with a signature of bad prognosis in BC patients [24] (Fig. 3d).

Recent work showed that the $\mathrm{ZnFn} 2$ GATA3 mutations interfere with the expression of the $P G R$ gene, coding for PR [6], while we observed that neoGATA3 mutations were associated with PR expression in tumors. We then examined several progesterone-related gene signatures and observed a downregulation in neoGATA3 tumors (Supplementary Fig. 5a) even when restricting the analysis to premenopausal patients, having higher progestogens levels (Fig. 3e). Interestingly, PGR was higher in neoGATA3 premenopausal tumors, compared to both WT $(P=0.01)$ and OtherMut $(P=0.005)$ (Supplementary Fig. 5b).

\section{The neoGATA3 protein is more stable and shows altered DNA binding}

To investigate the molecular mechanisms underlying the association of neoGATA3 mutations with good prognosis,

$n=65$, OtherMut $n=161)$. c Representative IHC images of CD8 $\alpha$ positive cells in one tumor with wt GATA3 and in one with neoGATA3. Quantification of the staining of WT $(n=6)$ and neoGATA3 $(n=9)$ tumors is shown under the microphotographs. Mann-Whitney $U$ test was used in $(\mathbf{a}, \mathbf{b})$, two-sided Student's $t$ test was used in (c) $* P<0.05, * * P<0.01$.

we searched for cellular models carrying the X308_Splice mutation. None of the analyzed $36 \mathrm{BC}$ cell lines, which included $10 \mathrm{ER}+$ lines, harbored this mutation, suggesting that cells with neoGATA3 mutations do not grow well in vitro. A collection of 90 PDX established from 81 patients was available [25]. While four of them carried a GATA3 mutation, it was never neoGATA3, indicating that tumors carrying these mutations are not efficiently established in mice. We then attempted to introduce the mutation in the endogenous locus of luminal BC cell lines, but failed to identify any successfully engineered clone among the 50 analyzed. Another report mentioned the difficulty of generating knock-in clones with a different GATA3 mutation [5] supporting a general lower fitness of GATA3-mutant $\mathrm{BC}$ cells in vitro. We therefore relied on lentiviral-based transduction of $\mathrm{BC}$ cells with HA-tagged neoGATA3 cDNA (HA-neoG3) and used Flag-tagged WT GATA3 cDNA (Flag-wtG3) or an empty vector as controls, to account for the effect of increased GATA3 protein dosage following neoGATA3 overexpression. 
a

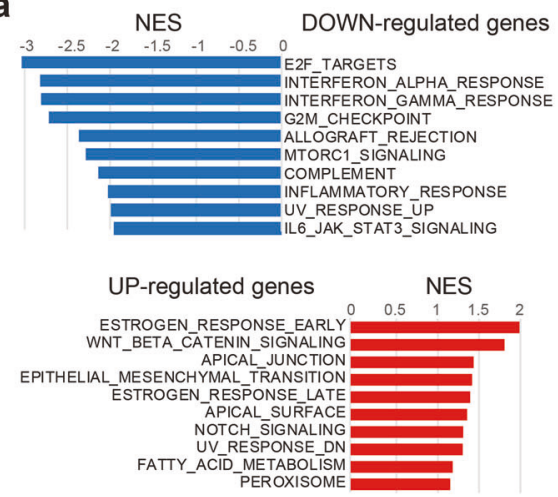

C

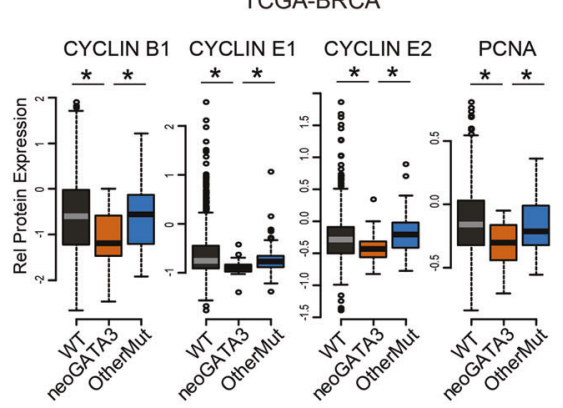

b

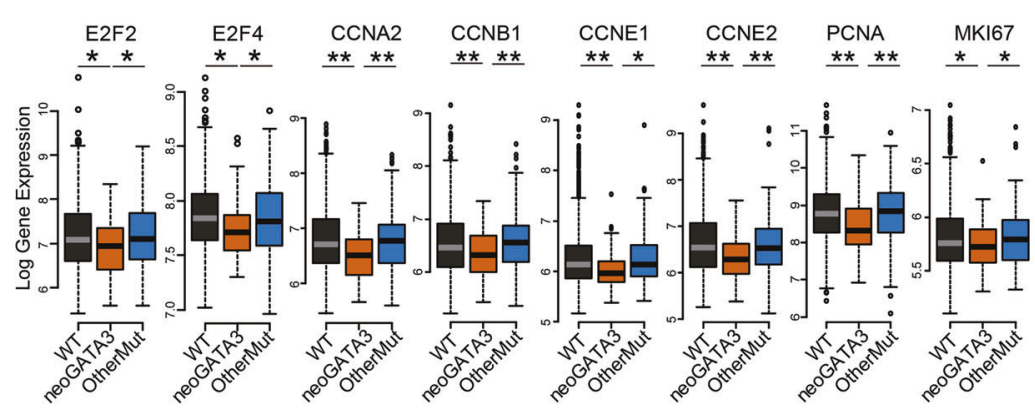

d
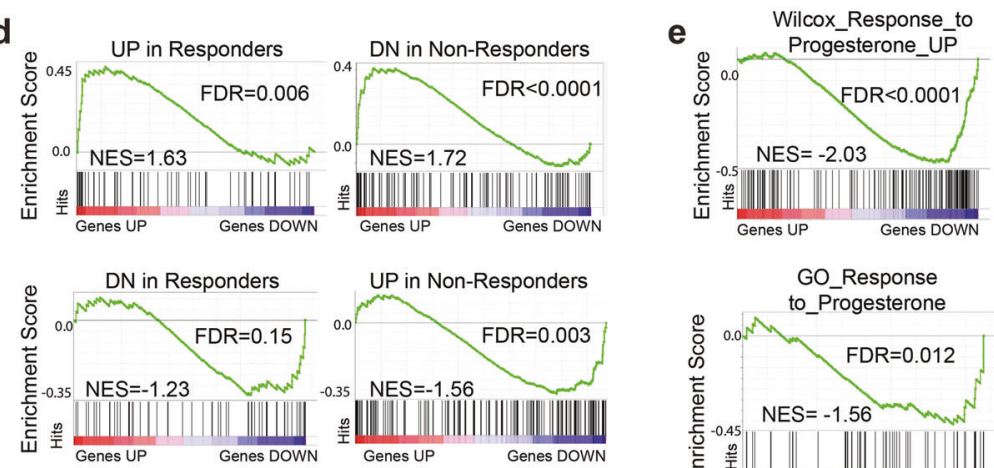

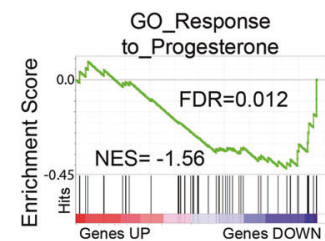

Fig. 3 NeoGATA3 is associated with altered ER-dependent transcriptional program. a GSEA on the ranked list of genes differentially regulated in neoGATA 3 tumors $(n=65)$ compared with all other tumors of the METABRIC ER + cohort $(n=1345)$. The "Hallmarks" collection of gene sets was interrogated. The graphs show the normalized enrichment score (NES) of the ten gene sets most significantly enriched among the upregulated (red) and the downregulated (blue) genes. FDR $<0.05$ for all gene sets shown. b Gene expression data for the indicated cell cycle-related genes in the METABRIC ER + patients belonging to the three groups (WT $n=1189$, neoGATA3 $n=66$, OtherMut $n=155$ ). c RPPA data from the TCGA cohort showing

Expression of HA-neoG3 or Flag-wtG3 in GATA3negative BT20 (Fig. 1c) and MDA-MB-468 cells (Supplementary Fig. 6a), followed by cycloheximide treatment, revealed that neoGATA3 is markedly more stable than the WT protein (estimated half-life $>16 \mathrm{~h}$ vs. $2 \mathrm{~h}$, respectively) (Fig. 4a and Supplementary Fig. 6b). Importantly, this was not dependent on the tags, since we observed a similar effect with untagged proteins (Supplementary Fig. 6b). GATA3 stability is regulated by the proteasome through progesterone-induced phosphorylation of the $\mathrm{S} 308$ residue, missing in neoGATA3 [26]. Accordingly, treatment with the proteasome inhibitor MG132 increased the half-life of wtGATA3 but not of neoGATA3 (Supplementary Fig. 6c). Consistent with the IHC findings in tumors (Fig. 1d) neoGATA3 properly localized to the nucleus even in the absence of endogenous GATA3 (Fig. 4b and Supplementary Fig. 6d, e). However, unlike wtGATA3, purified neoGATA3 - which lacks the C-terminal Zn finger essential for expression levels of the indicated proteins in the three tumor groups (WT $n=533$, neoGATA3 $n=18$, OtherMut $n=75$ ). d Enrichment plots for genesets defined by Ross-Innes et al. comparing gene expression in tumors responding to endocrine therapy and tumors with poor response. GSEA was performed on genes differentially regulated in the neoGATA3 tumors from the METABRIC ER + cohort. e Enrichment plots for two progesterone-related genesets among the differentially expressed genes in the METABRIC neoGATA3 patients compared to all other METABRIC ER+. Mann-Whitney $U$ test was used in $(\mathbf{b}, \mathbf{c}) . * P<0.05, * * P<0.01$.

DNA binding - showed only a weak binding to an oligonucleotide containing two palindromic GATAA motifs in an EMSA assay (Fig. 4c and Supplementary Fig. 6f). Accordingly, neoGATA3 was unable to modulate the promoter activity of $C D H 1$ and $C D H 3$, two known GATA3 targets [27, 28], in HEK293 cells using luciferase promoter reporter assays (Fig. 4d). Stable wtGATA3 expression in BT20 cells inhibited proliferation $(P=0.054)$ and BrdU incorporation $(P=0.012)$ (Fig. 4e) while neoGATA3 expression did not (Fig. 4e). Similar results were obtained in MDA-MB-468 cells (Supplementary Fig. 6g).

\section{NeoGATA3 interferes with the response to estradiol in ER + breast cancer cells}

Because neoGATA3 mutations are exclusively found in ER + tumors (Supplementary Fig. 3b), we assessed neoGATA3 function in T47D and ZR75-1, two ER + /GATA3 + BC 
a

BT20

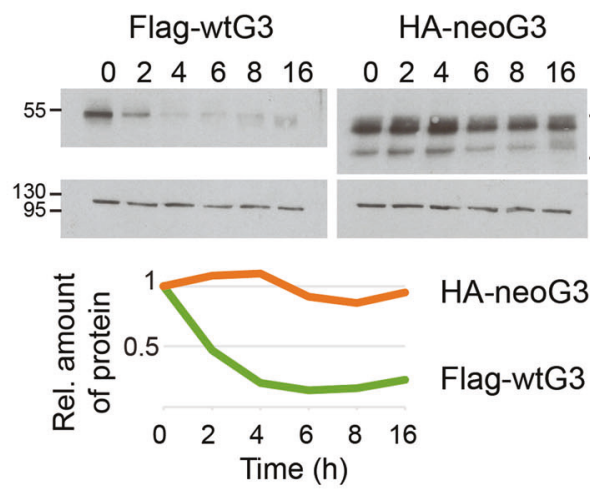

C

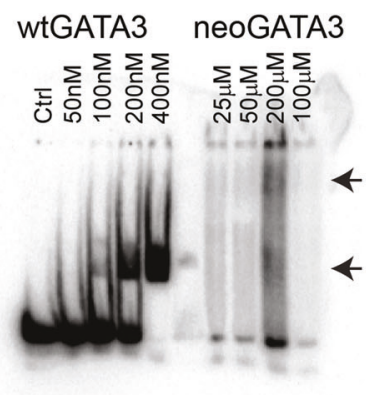

d

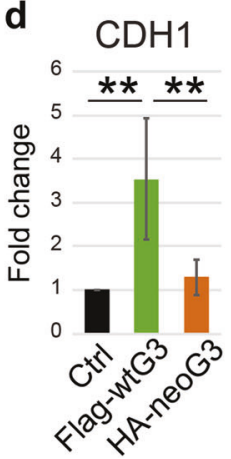

b

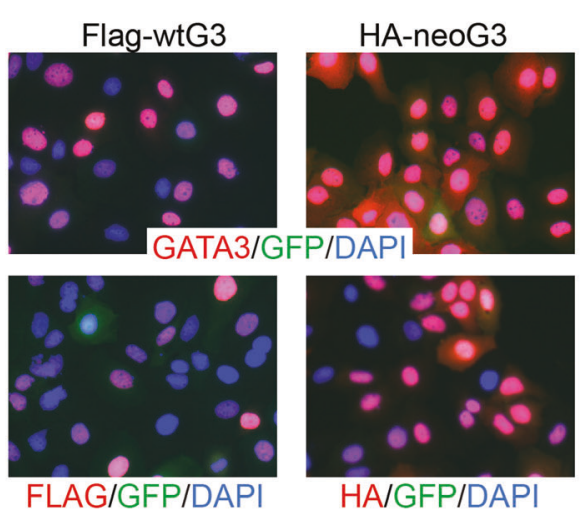

Fig. 4 Biochemical and functional characteristics of neoGATA3 differ from wtGATA3. a Western blot showing the expression of wtGATA3 or neoGATA3 upon gene transduction in the GATA3negative BT20 cells, after treatment with $50 \mu \mathrm{g} / \mathrm{ml}$ cycloheximide (CHX) for the indicated time. Vinculin was used as loading control. Quantification of relative band intensity is shown at the bottom. Images are representative of at least three independent experiments. b Immunofluorescence using the N-ter GATA3 antibody (top panels) or tag-specific antibodies (bottom panels, left: Flag, right: HA) in BT20 cells expressing either Flag-wtG3 or HA-neoG3, as indicated. DAPI was used to counterstain nuclei, GFP was expressed by the lentiviral vector used for the transduction. $\mathbf{c}$ EMSA assay performed

cell lines (Supplementary Fig. 7a). NeoGATA3 was more stable also in this context and the stability of endogenous GATA3 was not affected by the mutant (Fig. 5a, estimated half-life: $>8 \mathrm{~h}$ vs $2 \mathrm{~h}$ ). This is consistent with the observation that, in the TCGA-BRCA series, total GATA3 protein levels were significantly higher in the neoGATA3-mutant vs. WT tumors $(P=1.72 \mathrm{e}-07)$ [3] (Fig. 5b). Overexpression of wtGATA3 or neoGATA3 had no significant effect on proliferation and wound healing capacity of T47D and ZR75-1 cells (Supplementary Fig. 7b, c).

The patient-based transcriptomics analyses suggested that neoGATA3 modulates the ER-dependent program. Treatment of hormone-depleted control T47D cells with $17 \beta$-estradiol (E2) induced proliferation at $24-72 \mathrm{~h}$, which was blunted by $4 \mathrm{OH}-\mathrm{Tamoxifen}$ (TMX). By contrast, neoGATA3-expressing cells showed a significantly lower response to E2 $(P=0.025)($ Fig. $5 \mathrm{c}, \mathrm{d})$. WtGATA3- with recombinant wtGATA3 or neoGATA3 and DNA fragment containing two GATAA motifs. d Reporter assay using the promoter regions of either $\mathrm{CDH} 1$ or $\mathrm{CDH} 3$ upstream of the luciferase cDNA. HEK293 cells were transiently transfected with the indicated constructs and luciferase activity was measured after $48 \mathrm{~h}$. A GFPexpressing plasmid was co-transfected to normalize for transfection efficiency by western blotting (not shown). e Growth curve (left) and percentage of BrdU+ cells (right) measured in BT20 cells transduced with the indicated constructs. Data are represented as mean \pm standard deviation of at least three independent experiments. Two-sided Student's $t$ test $* P<0.05, * * P<0.01$.

overexpressing cells showed an intermediate phenotype (Fig. 5c, d). Similar, although less prominent, findings were made using ZR75-1 cells (Supplementary Fig. 8a, b). This observation was at odds with the enrichment of the two "Estrogen response" Hallmarks genes sets among overexpressed genes in the neoGATA3 tumors from patients. However, the Hallmarks gene sets do not discriminate between up- or down-regulated genes, therefore we performed GSEA on the METABRIC gene expression dataset, using an ad-hoc subset of estradiol- and TMXrelated signatures selected from the MSigDb, with separate up- and down-regulated genes. The two signatures "Dutertre_E2_6h_UP" and "Dutertre_E2_24h_UP", corresponding to genes upregulated in MCF7 $\mathrm{BC}$ cells upon E2 stimulation for $6 \mathrm{~h}$ or $24 \mathrm{~h}$, respectively, were significantly enriched among the genes downregulated in neoGATA3 tumors, consistent with our in vitro 
a

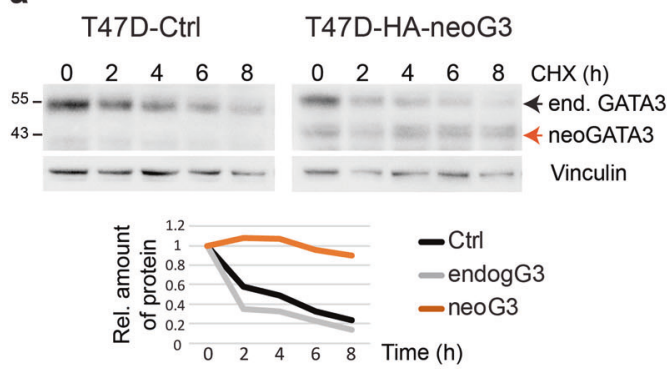

b

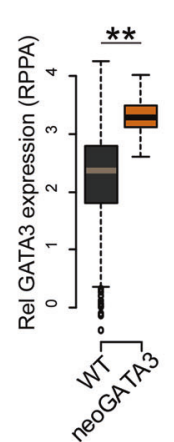

C

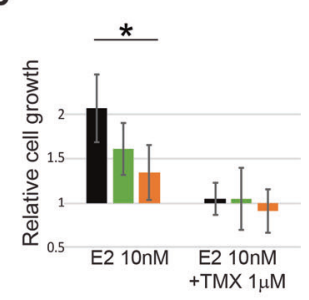

Ctrl Flag-wtG3 $\square$ HA-neoG3 d

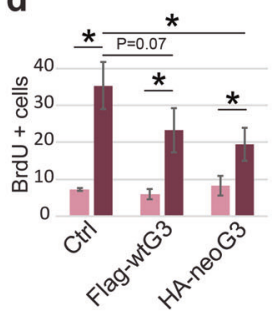

e

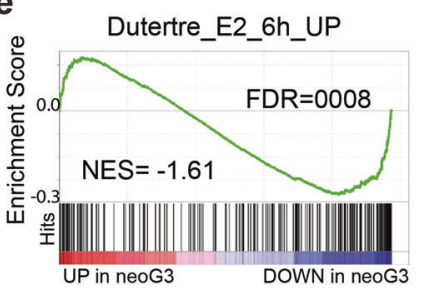

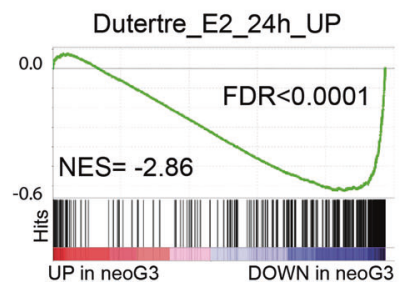

UP in neoG3

DOWN in neoG3

Fig. 5 NeoGATA3 interferes with response to estradiol in ER + cells. a Western blot showing the expression of endogenous GATA3 or ectopically expressed neoGATA3 in T47D cells treated with $50 \mu \mathrm{g} /$ $\mathrm{ml}$ CHX for the indicated time. Vinculin was used as loading control. Quantification of relative band intensity is shown at the bottom. The endogenous GATA3 band was quantified as well in the neoGATA3transduced cells. The images are representative of at least three independent experiments. b RPPA data from the TCGA cohort showing GATA3 expression levels in tumors of the three groups of patients (WT $n=533$, neoGATA3 $n=18$ ). c Graphs showing the relative cell growth of T47D cells transduced with the indicated constructs, after $48 \mathrm{~h}$ in hormone-depleted (HD) medium followed by $72 \mathrm{~h}$ of treatment with $\mathrm{E} 2(10 \mathrm{nM})$ or with $\mathrm{E} 2(10 \mathrm{nM})$ and TMX $(1 \mu \mathrm{M})$. All values are

observations (Fig. 5e). These data, together with the concordance between lower E2-induced proliferation in vitro and better outcome in patients, support the use of cell lines in vitro to investigate neoGATA3 function. Of note, gene expression signatures related to resistance to TMX in BC cell lines were also regulated in the neoGATA3 tumors (Fig. 5e).

\section{Genomic binding of ER is altered in neoGATA3-expressing cells}

To understand how neoGATA3 interferes with the ERdependent program, we checked the modulation of the ER protein upon hormone starvation and subsequent stimulation with E2 or TMX, which induce a reduction and an increase of ER, respectively [17]. NeoGATA3 expression did not affect the total ER levels in any of the tested conditions in T47D cells (Supplementary Fig. 8c, d).

No difference was observed in chromatin-bound ER in hormone-starved T47D cells expressing neoGATA3 compared to Ctrl or wtGATA3-overexpressing cells. However, after stimulation with $10 \mathrm{nM}$ E2 the drop in chromatinbound ER was significantly more pronounced in

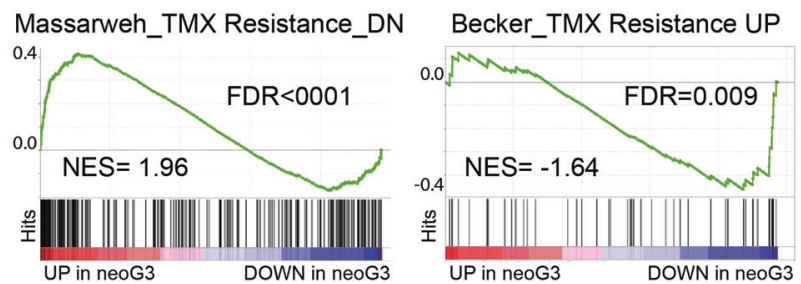

normalized to vehicle-treated cells of each experimental group. Data are represented as mean \pm standard deviation of at least three independent experiments. Two-sided Student's $t$ test $* P<0.05$ compared with treated Ctrl cells, ${ }^{\#} P<0.05$ compared to vehicle-treated cells of the same experimental group. d Graphs showing the percentage of BrdU-positive nuclei in T47D cells transduced with the indicated constructs, after $48 \mathrm{~h}$ in HD medium followed by $24 \mathrm{~h}$ treatment with E2 $(10 \mathrm{nM})$ or with vehicle. Data are represented as mean \pm standard deviation of at least three independent experiments. Two-sided Student's $t$ test showed no statistically significant differences. e Enrichment plots for genesets related with estradiol stimulation and tamoxifen resistance in vivo. GSEA was performed on genes differentially expressed in METABRIC neoGATA3 tumors.

neoGATA3-expressing cells compared to both $\mathrm{Ctrl}(P=$ 0.036) and wtGATA3-overexpressing cells $(P=0.016)$ suggesting that neoGATA3 interferes with the genomic binding of ER to some of its targets upon estrogen stimulation (Fig. 6a).

We then assessed the genomic localization of ER in Ctrl or neoGATA3-expressing T47D cells with ChIP-Seq, after $48 \mathrm{~h}$ of hormone starvation followed by stimulation with $10 \mathrm{nM}$ E2. When merging replicates (Supplementary Fig. 9a) the total number of ER peaks was slightly reduced in neoGATA3 cells (7710) compared with Ctrl cells (9096) and 5591/7710 peaks (72.5\%) were overlapping with peaks detected in Ctrl cells. Visual inspection of a set of peaks showed reduced signal in neoGATA3-expressing cells (Fig. 6b and Supplementary Fig. 9b-f). Differential binding analysis revealed that most of the common peaks had reduced ER enrichment in neoGATA3-expressing cells, with 1253 peaks showing significantly reduced binding, and only one peak with significantly higher binding (Fig. 6c). This is in accordance with an overall reduced binding of ER to the chromatin after stimulation with estrogen (Fig. 6a). Interestingly, 26.9\% of all ER peaks but only $9.9 \%$ of those with reduced ER enrichment 
a
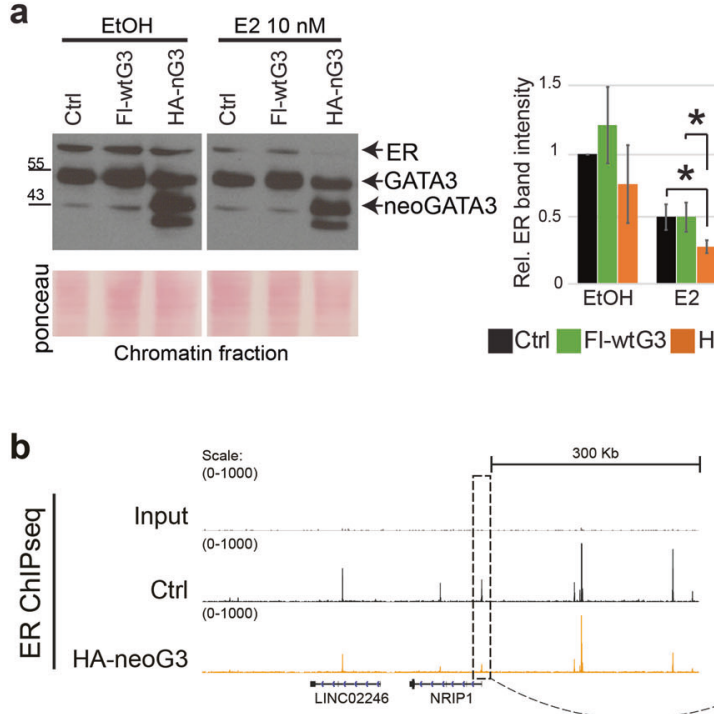

C

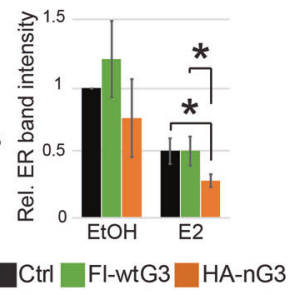

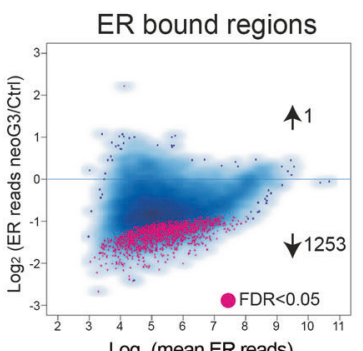

$\log _{2}$ (mean ER reads) d

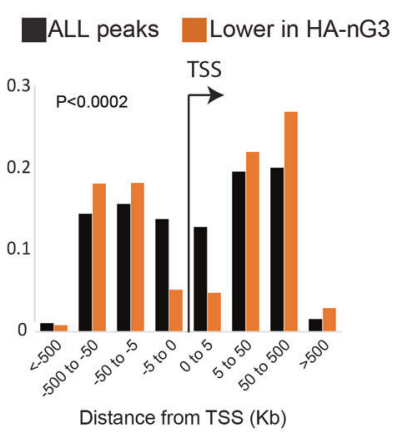

f

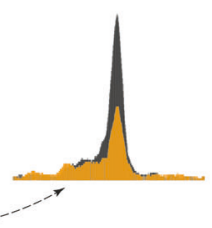

ER bound genes (+/-25bp around TSS)

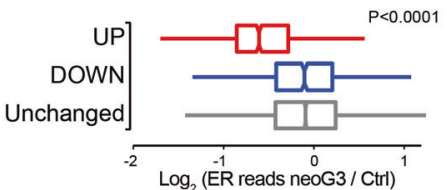

e
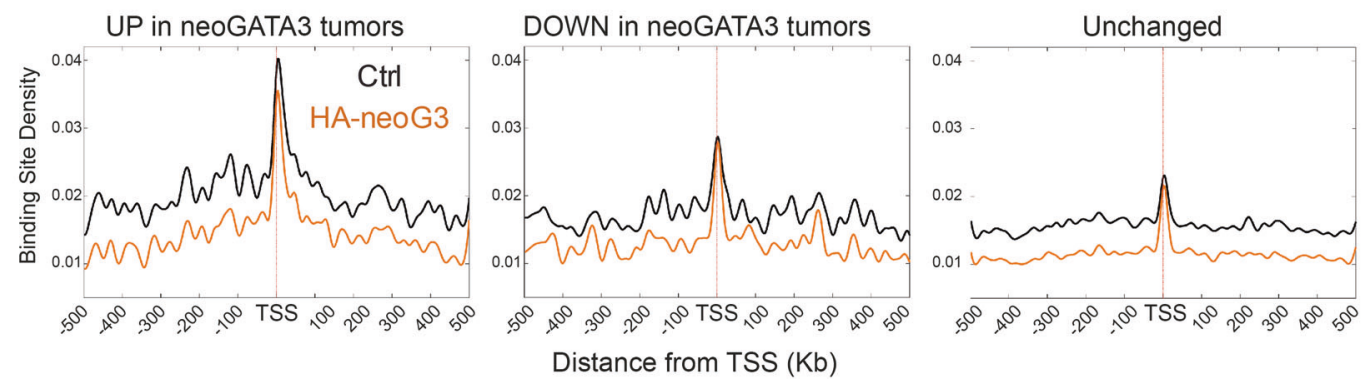

Fig. 6 NeoGATA3 reduces the binding of ER to chromatin. a Western blot showing chromatin-bound ER and GATA3 in T47D cells transduced with the indicated constructs and treated as indicated for $24 \mathrm{~h}$ after $48 \mathrm{~h}$ in HD medium. Ponceau staining was used to assess equal loading. The quantification of the ER band intensity from three independent experiments is shown below. b Visualization of ChIP-Seq results in the genome browser. Magnification of the region in the box shows reduced ER signal in neoGATA3-expressing cells at the TSS of NRIP1. c Plot showing the differential binding of ER in Ctrl versus neoGATA3-expressing T47D cells. In pink are the peaks that show significantly reduced or increased ER enrichment in neoGATA3 cells calculated with DiffBind analysis. d Distribution of all peaks and peaks with reduced ER enrichment in neoGATA3 cells across the indicated intervals of distance from the TSS of the gene annotated to the peak. Chi-square test for differences in frequencies was applied. e ER binding density plot showing the enrichment of ER at ChIP-Seq peaks in Ctrl (black) and neoGATA3-expressing (orange) T47D cells considering genes that are upregulated, downregulated, or unchanged in the METABRIC ER+neoGATA3 tumors. f Box-plots show Log2 fold changes of normalized ER signals in neoGATA3-expressing T47D cells compared to controls. Signals were analyzed in regions \pm $25 \mathrm{bp}$ around TSS of genes that were upregulated $(n=999)$, downregulated $(n=921)$, or unchanged $(n=11537)$ in METABRIC neoGATA3 tumors. The signals are average values from ChIP-seq experiments in three biological replicates. Kruskal-Wallis $P<0.0001$. in neoGATA3-expressing cells were located within $5 \mathrm{~kb}$ from a TSS (Fig. 6d, $P<0.002$ ) suggesting that neoGATA3 influences mostly the fine tuning of ER-dependent transcription, consistent with the subtle differences we observed in these cells.

To evaluate the extent to which our observations in T47D cells might reflect the scenario in patients, we analyzed the ER binding density in Ctrl and neoGATA3expressing T47D cells at ChIP-Seq peaks located around the TSS of genes that were differentially expressed in neoGATA3 tumors from the METABRIC cohort. The binding density of ER peaks in neoGATA3-expressing cells was especially reduced on distal regions, independently from the resulting transcriptional effect (Fig. 6e).
Interestingly, the binding density of peaks located at the TSS of genes that were either unchanged or downregulated in neoGATA3 tumors was maintained in neoGATA3-expressing T47D cells, but lower on the TSS of genes upregulated in neoGATA3 tumors (Fig. 6e, f). This suggests that neoGATA3 partially interferes with ER binding especially at enhancers and at the TSS of ER target genes that are repressed by ER. Of note, ER binding intensity in Ctrl T47D cells was generally higher on genes that were differentially expressed in neoGATA3 tumors compared to unchanged genes, supporting the use of this cellular model to understand neoGATA3 function in the context of ER-dependent transcription. 


\section{NeoGATA3 interferes with progesterone-induced growth arrest}

While the essential role of GATA3 for ER activity is well known, its relation with PR is much less studied. NeoGATA3 appeared to interfere with the transcriptional response to progesterone in tumors, especially in premenopause (Fig. 3e and Supplementary Fig. 5a). We therefore investigated the role of neoGATA3 in the PR-dependent program. As reported [6], hyperstimulation with P4 induced growth arrest in T47D cells, measured as BrdU incorporation after $24 \mathrm{~h}$ (Fig. 7a) and as cell viability after 6 days (Fig. 7b). This growth arrest was significantly reduced in neoGATA3expressing cells both at $24 \mathrm{~h}(P=0.041)$ and after 6 days $(P=0.007)$. When the $\mathrm{P} 4$-arrested cells were changed back to normal medium, with lower progesterone levels, for 3 additional days, both control and wtGATA3-overexpressing cells partially recovered proliferation, while neoGATA3expressing cells remained arrested (Fig. 7b).

Interestingly, both GATA3 and neoGATA3 (in neoGATA3-expressing cells) were strikingly more abundant in the PR complex than in the ER complex, as shown by co-immunoprecipitation (Supplementary Fig. 10). Consistent with the lack of S308 in the neoGATA3, its expression was not reduced after treatment with $100 \mathrm{nM}$ progesterone ( $\mathrm{P} 4)$ for $24 \mathrm{~h}$, as opposed to endogenous GATA3 both in Ctrl and in neoGATA3-expressing cells (Fig. 7c). Interestingly, exogenous wtGATA3 was not reduced upon $\mathrm{P} 4$ treatment, possibly due to the overexpression of the protein from an ectopic promoter, evading the PR-dependent transcriptional inhibition [26].

\section{Discussion}

GATA3 is a paradigm of how genetic alterations in a given gene should not be lumped into a single class $[5,6]$. Our work adds an important concept, namely that a single mutation might have distinct functions, depending on the context of the disease. This calls for an exhaustive functional characterization to refine our understanding of driver mutations roles and improve clinical application.

The GATA3 X308_Splice mutation is predicted to produce a mutant protein lacking the second $\mathrm{ZnFn}$ and carrying a unique 44aa peptide (neoGATA3). Importantly, we identified five additional mutations predicted to generate a protein with partially or fully identical C-terminal peptides, supporting a selective pressure toward convergent oncogenic evolution. Here we provide formal proof, using a novel peptide-specific antibody, that neoGATA3 mutations are associated with less aggressive tumors and better outcome in patients. In vitro, neoGATA3 interferes with ER genomic binding upon estrogen stimulation, especially at enhancer regions. In addition, neoGATA3 interferes with the PR-dependent antiproliferative program in a progesterone-high context.

To understand the molecular function of neoGATA3 mutations in $\mathrm{BC}$, we turned to an in vitro model. NeoGATA3 mutations are typically heterozygous, and the wtGATA3 protein is still expressed. Unfortunately, we did not manage to find or generate any cellular model carrying the mutation in the endogenous locus, therefore we decided to use lentiviral transduction of ER + cell lines. To control for increased abundance of total GATA3 proteins, we included wtGATA3-transduced cells. Indeed, the latter often showed an intermediate phenotype between $\mathrm{Ctrl}$ and neoGATA3-expressing cells, highlighting the limitations of our model. This might also suggest that part of the neoGATA3-dependent effects are simply due to its higher stability. Importantly, the major findings from our in vitro experiments were consistent with patient-based observations and we believe that our in vitro system is informative despite its limitations. Given the prevalence of neoGATA3 mutations in patients, the lack of models carrying them endogenously is striking and suggests that these alterations are likely weak drivers, conferring mild proliferative advantage only in specific contexts that are not easily reproduced ex vivo or in vitro.

The unique C-terminal peptide of neoGATA3 is a predicted neoantigen [21] proposed to be associated with increased T-cell-mediated immune response [29]. A neoantigen-elicited tumor clearance by the immune system would be an appealing explanation for the better outcome observed in patients carrying neoGATA 3 mutations. However, we did not find evidence for this using multiple methods of analysis. The tumor immune milieu is indeed altered in neoGATA3 tumors, but the exact contribution of the immune infiltrates to their phenotype and whether/how neoGATA3 directly or indirectly influences the tumor microenvironment remains to be understood.

Our analyses of patient-derived datasets highlighted the ER-dependent transcriptome as highly altered in neoGATA3 tumors, in line with the known function of GATA3 as a crucial ER co-factor [11]. Indeed neoGATA3 expression reduced, but did not fully abrogate, the response to estrogen in two $\mathrm{ER}+\mathrm{BC}$ cell lines. In particular, we observed a significant reduction of the chromatin-bound ER. In addition, ChIP-Seq revealed that the loss of ER binding was especially pronounced on regions far from the TSS, possibly enhancers. This suggests that neoGATA3 interferes mainly with the fine-tuning of ER-dependent transcription, consistent with the rather mild biological effects observed. As the C-terminal part of GATA3 is thought to modulate protein-protein interactions, the novel peptide contained in neoGATA3 could quench the formation of a functional DNA-binding ER complex or alter 
a
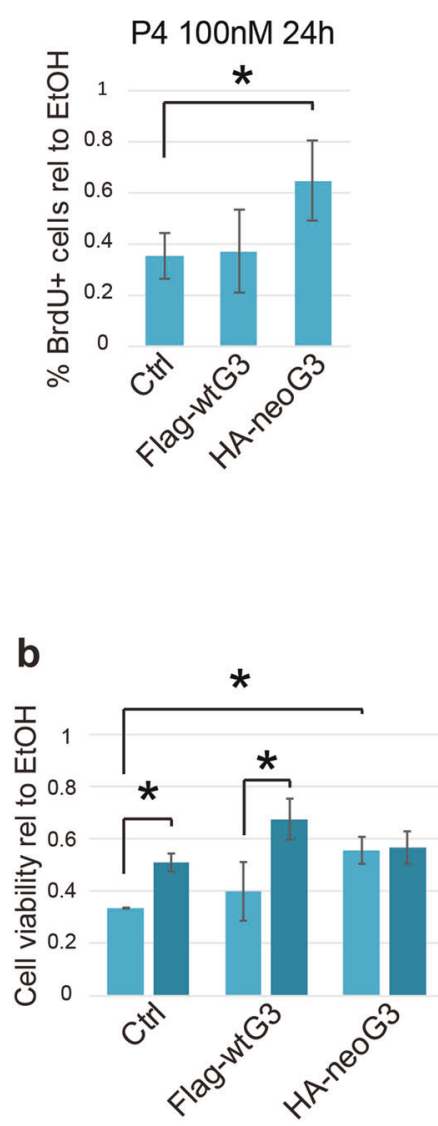

P4 100nM 6d

P4 100nM 3d + EtOH 3d
C

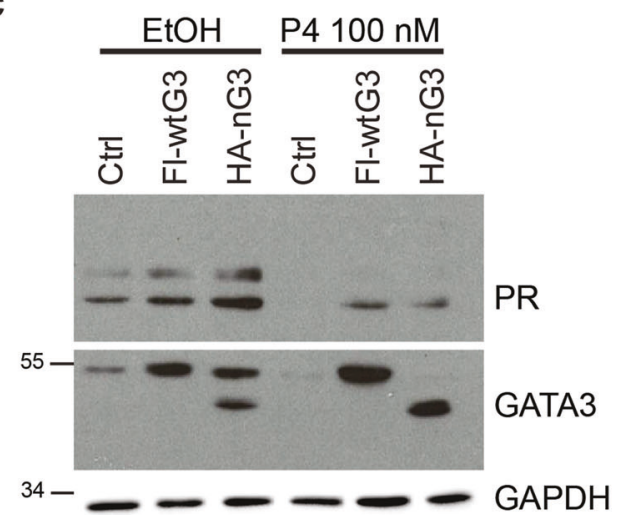

d

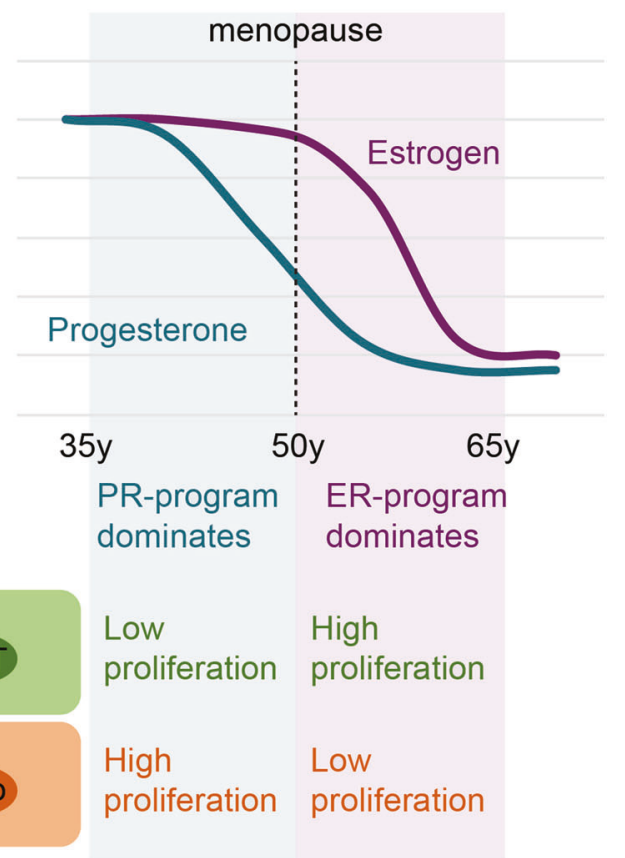

Fig. 7 NeoGATA3 interferes with the PR-dependent growth arrest. a Graph showing the relative percentage of BrdU+ cells in the indicated cell population after $24 \mathrm{~h}$ treatment with vehicle or $100 \mathrm{nM}$ P4. b Graph showing the relative cell viability measured with crystal violet staining of the indicated cell populations after vehicle-treatment, 6 days treatment with $100 \mathrm{nM} \mathrm{P} 4$, or 3 days with $100 \mathrm{nM}$ P4 followed by additional 3 days in normal medium. Cells were kept in normal medium containing hormones. In $\mathbf{a}, \mathbf{b}$ the results are normalized to the respective vehicle control and are shown as mean \pm standard deviation of at least three independent experiments. Two-sided Student's $t$ test $* P<0.05$. $\mathbf{c}$ Western blot showing expression of PR, wtGATA3, and

co-factors accessibility. Our analyses suggest that there might be a more obvious modulation of genes that are normally repressed by ER.

Having provided hints on the possible mechanism linking neoGATA 3 to better prognosis in patients, we were puzzled by the fact that the neoGATA3 mutations, unfavorable for tumor cells, are highly selected during tumor evolution. We reasoned that there might be a context in
neoGATA3 in T47D cells transduced with the indicated constructs and treated with progesterone $(\mathrm{P} 4)(100 \mathrm{nM})$ for $24 \mathrm{~h}$ in normal medium. GAPDH was used as loading control. d The working model: neoGATA3 is a weak oncogenic driver with highly context-dependent functions. In a progesterone-rich environment, it interferes with the antiproliferative PR-driven program, whereas in an estrogen-rich context it blunts the pro-mitogenic ER-dependent response. Progesterone drops faster than estrogen at menopause, therefore it is possible that neoGATA3 mutations are enriched in premenopause patients because of this context-dependent opposite effects.

which neoGATA3 grants a proliferative advantage. NeoGATA3 mutations are remarkably frequent among premenopausal patients, where estrogens and progestogens levels are relatively high and ER and PR have antagonistic effects through the modulation of shared targets [30]. GATA3 and PR are in the same protein complex [31] and PR reduces GATA3 both at transcriptional and post-translational levels, in particular by inducing 
phosphorylation of S308, which prompts GATA3 ubiquitination [26]. The strong selection of mutations abrogating this residue points toward a function in evading the PRdependent antiproliferative program as we observed in T47D, where progesterone-induced growth arrest was less prominent in neoGATA3-expressing cells. Interestingly, wtGATA3 expression in T47D cells from an ectopic promoter evading PR-dependent transcriptional inhibition showed a tendency to reduce progesterone-induced growth arrest and 4 of the 5 neoGATA3-like mutations retain the S308 residue and are therefore likely degraded in response to progesterone. This would indicate that the increased stability of neoGATA3 is not the only explanation for the interference with PR function. Our data suggest that GATA3 is a crucial co-factor for both ER and PR and further-omics studies should be performed to assess its precise role in their transcriptional programs.

Intriguingly, the wtGATA3 was expressed at lower levels than neoGATA3 in T47D cells, yet wtGATA3transduced cells often showed intermediate phenotypes between Ctrl-transduced and neoGATA3-expressing cells. This would suggest that an increase in GATA3 expression is sufficient to disrupt the balance between ER and PR programs, and that neoGATA3 is less efficient than the WT protein at doing this. Therefore, neoGATA3 behaves as a weak, inefficient, oncogenic driver.

In conclusion, our data suggest that neoGATA3 mutations are specifically selected in a molecular context where estrogen-driven mitogenic phenotypes are counterbalanced by progesterone-driven antiproliferative effects. In this scenario, the net output of neoGATA3 interference with both ER and PR programs seems to be a proliferative advantage. On the other hand, in a context where the ER-dependent program dominates, neoGATA3 confers a proliferative disadvantage and is associated with better patient outcome (Fig. 7d). The neoGATA3 mutations therefore represent a subtype of context-dependent weak driver mutations associated with distinct clinical features.

\section{Methods}

\section{Patient samples and patient-related information}

FFPE sections, DNA, RNA, and protein lysates from BC samples were obtained from the CRUK Cambridge, the Hospital INCLIVA (Valencia), and the Hospital Vall d'Hebron (Barcelona). Transciptomic data from TCGA and METABRIC were downloaded from cbioportal.org. All procedures were approved by the institutional Ethics Committees and informed consent was obtained from all patients.
Acknowledgements We want to thank G. Timelthaler, M.A. Quintela, and F. Reyal for valuable contributions, J. Valcárcel, J. Muñoz-Pérez, and O. Domínguez for discussions.

Funding Work in the lab of PM was supported by the Institute of Cancer Research of the Medical University Vienna and by the grant P27361-B23 from the Austrian Science Grant (FWF), FXR was supported by SAF2011-29530 and SAF2015-70553-R grants from Ministerio de Economía y Competitividad (Madrid, Spain) (co-funded by the ERDF-EU), Fundación Científica de la Asociación Española Contra el Cáncer. CNIO is supported by Ministerio de Ciencia, Innovación y Universidades as a Centro de Excelencia Severo Ochoa SEV-2015-0510. Work in the lab of JSC and CC was supported by Cancer Research UK. Work in the lab of SRM was supported by the Spanish Ministry of Science, Innovation and Universities (BFU201680570-R; AEI/FEDER, UE).

Author contributions PM and FXR conceptualized the study, acquired funding, and prepared the paper. PM designed, performed, and analyzed most of the experiments. $\mathrm{NH}$ and $\mathrm{MK}$ performed crucial experiments. AP and JSC contributed to the design of the experiments and to the paper preparation. MS, OGC, FDCO, LPR, AS, ADR, IC, JS, SRM, and BK performed some of the experiments. AP, OB, SFC, $\mathrm{CC}, \mathrm{JMC}$, and $\mathrm{BB}$ provided patient-derived samples and data. DA generated the polyclonal antibody.

\section{Compliance with ethical standards}

Conflict of interest The authors declare that they have no conflict of interest.

Publisher's note Springer Nature remains neutral with regard to jurisdictional claims in published maps and institutional affiliations.

Open Access This article is licensed under a Creative Commons Attribution 4.0 International License, which permits use, sharing, adaptation, distribution and reproduction in any medium or format, as long as you give appropriate credit to the original author(s) and the source, provide a link to the Creative Commons license, and indicate if changes were made. The images or other third party material in this article are included in the article's Creative Commons license, unless indicated otherwise in a credit line to the material. If material is not included in the article's Creative Commons license and your intended use is not permitted by statutory regulation or exceeds the permitted use, you will need to obtain permission directly from the copyright holder. To view a copy of this license, visit http://creativecommons. org/licenses/by/4.0/.

\section{References}

1. Chin L, Hahn WC, Getz G, Meyerson M. Making sense of cancer genomic data. Genes Dev. 2011;25:534-55.

2. Pereira B, Chin SF, Rueda OM, Vollan HK, Provenzano E, Bardwell HA, et al. The somatic mutation profiles of 2,433 breast cancers refines their genomic and transcriptomic landscapes. Nat Commun. 2016;7:11479.

3. Cancer Genome Atlas Network. Comprehensive molecular portraits of human breast tumours. Nature. 2012;490:61-70.

4. Curtis C, Shah SP, Chin SF, Turashvili G, Rueda OM, Dunning $\mathrm{MJ}$, et al. The genomic and transcriptomic architecture of 2,000 breast tumours reveals novel subgroups. Nature. 2012;486:346-52.

5. Mair B, Konopka T, Kerzendorfer C, Sleiman K, Salic S, Serra V, et al. Gain- and loss-of-function mutations in the breast cancer 
gene GATA3 result in differential drug sensitivity. PLoS Genet. 2016;12:e1006279.

6. Takaku M, Grimm SA, Roberts JD, Chrysovergis K, Bennett BD, Myers P, et al. GATA3 zinc finger 2 mutations reprogram the breast cancer transcriptional network. Nat Commun. 2018;9:1059.

7. Takaku M, Grimm SA, Wade PA. GATA3 in breast cancer: tumor suppressor or oncogene? Gene Expr. 2015;16:163-8.

8. Cohen H, Ben-Hamo R, Gidoni M, Yitzhaki I, Kozol R, Zilberberg A, et al. Shift in GATA3 functions, and GATA3 mutations, control progression and clinical presentation in breast cancer. Breast Cancer Res. 2014;16:464.

9. Kouros-Mehr H, Slorach EM, Sternlicht MD, Werb Z. GATA-3 maintains the differentiation of the luminal cell fate in the mammary gland. Cell. 2006;127:1041-55.

10. Eeckhoute J, Keeton EK, Lupien M, Krum SA, Carroll JS, Brown M. Positive cross-regulatory loop ties GATA-3 to estrogen receptor alpha expression in breast cancer. Cancer Res. 2007;67:6477-83.

11. Theodorou V, Stark R, Menon S, Carroll JS. GATA3 acts upstream of FOXA1 in mediating ESR1 binding by shaping enhancer accessibility. Genome Res. 2013;23:12-22.

12. Kong SL, Li G, Loh SL, Sung WK, Liu ET. Cellular reprogramming by the conjoint action of ERalpha, FOXA1, and GATA3 to a ligand-inducible growth state. Mol Syst Biol. 2011;7:526.

13. Kouros-Mehr H, Bechis SK, Slorach EM, Littlepage LE, Egeblad M, Ewald AJ, et al. GATA-3 links tumor differentiation and dissemination in a luminal breast cancer model. Cancer Cell. 2008; 13:141-52.

14. Usary J, Llaca V, Karaca G, Presswala S, Karaca M, He X, et al. Mutation of GATA3 in human breast tumors. Oncogene. 2004;23:7669-78.

15. Gustin JP, Miller J, Farag M, Rosen DM, Thomas M, Scharpf RB, et al. GATA3 frameshift mutation promotes tumor growth in human luminal breast cancer cells and induces transcriptional changes seen in primary GATA3 mutant breast cancers. Oncotarget. 2017;8:103415-27.

16. Ellis MJ, Ding L, Shen D, Luo J, Suman VJ, Wallis JW, et al. Whole-genome analysis informs breast cancer response to aromatase inhibition. Nature. 2012;486:353-60.

17. Adomas AB, Grimm SA, Malone C, Takaku M, Sims JK, Wade PA. Breast tumor specific mutation in GATA3 affects physiological mechanisms regulating transcription factor turnover. BMC Cancer. 2014;14:278.

18. Sorlie T, Perou CM, Tibshirani R, Aas T, Geisler S, Johnsen H, et al. Gene expression patterns of breast carcinomas distinguish tumor subclasses with clinical implications. Proc Natl Acad Sci USA. 2001;98:10869-74.
19. Zehir A, Benayed R, Shah RH, Syed A, Middha S, Kim HR, et al. Mutational landscape of metastatic cancer revealed from prospective clinical sequencing of 10,000 patients. Nat Med. 2017;23:703-13.

20. Prat A, Parker JS, Fan C, Cheang MC, Miller LD, Bergh J, et al. Concordance among gene expression-based predictors for ERpositive breast cancer treated with adjuvant tamoxifen. Ann Oncol. 2012;23:2866-73.

21. Jayasinghe RG, Cao S, Gao Q, Wendl MC, Vo NS, Reynolds SM, et al. Systematic Analysis of Splice-Site-Creating Mutations in Cancer. Cell Rep. 2018;23:270-81. e273.

22. Becht E, Giraldo NA, Lacroix L, Buttard B, Elarouci N, Petitprez $\mathrm{F}$, et al. Estimating the population abundance of tissue-infiltrating immune and stromal cell populations using gene expression. Genome Biol. 2016;17:218.

23. Thorsson V, Gibbs DL, Brown SD, Wolf D, Bortone DS, Ou Yang TH, et al. The Immune Landscape of Cancer. Immunity. 2018;48:812-30. e814.

24. Ross-Innes CS, Stark R, Teschendorff AE, Holmes KA, Ali HR, Dunning MJ, et al. Differential oestrogen receptor binding is associated with clinical outcome in breast cancer. Nature. 2012;481:389-93.

25. Bruna A, Rueda OM, Greenwood W, Batra AS, Callari M, Batra $\mathrm{RN}$, et al. A biobank of breast cancer explants with preserved intra-tumor heterogeneity to screen anticancer compounds. Cell. 2016;167:260-74. e222.

26. Izzo F, Mercogliano F, Venturutti L, Tkach M, Inurrigarro G, Schillaci R, et al. Progesterone receptor activation downregulates GATA3 by transcriptional repression and increased protein turnover promoting breast tumor growth. Breast Cancer Res. 2014;16:491.

27. Tkocz D, Crawford NT, Buckley NE, Berry FB, Kennedy RD, Gorski JJ, et al. BRCA1 and GATA3 corepress FOXC1 to inhibit the pathogenesis of basal-like breast cancers. Oncogene. 2012;31:3667-78.

28. Yan W, Cao QJ, Arenas RB, Bentley B, Shao R. GATA3 inhibits breast cancer metastasis through the reversal of epithelialmesenchymal transition. J Biol Chem. 2010;285:14042-51.

29. Turajlic S, Litchfield K, Xu H, Rosenthal R, McGranahan N, Reading JL, et al. Insertion-and-deletion-derived tumour-specific neoantigens and the immunogenic phenotype: a pan-cancer analysis. Lancet Oncol. 2017;18:1009-21.

30. Singhal H, Greene ME, Tarulli G, Zarnke AL, Bourgo RJ, Laine $\mathrm{M}$, et al. Genomic agonism and phenotypic antagonism between estrogen and progesterone receptors in breast cancer. Sci Adv. 2016;2:e1501924.

31. Mohammed H, Russell IA, Stark R, Rueda OM, Hickey TE, Tarulli GA, et al. Progesterone receptor modulates ERalpha action in breast cancer. Nature. 2015;523:313-7. 